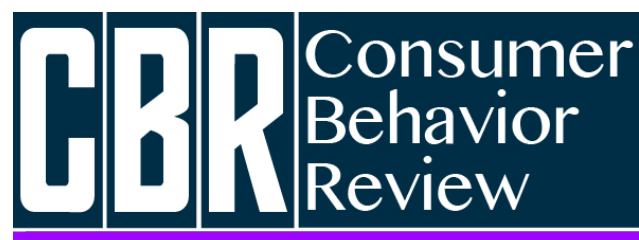

Revista Comportamento do Consumidor
Monteiro, R. A. S., \& Araujo, F. F. (2020). Produção de Sentidos na Indústria Cultural da Cerveja: Aspectos do processo discursivo nas ações de marketing de experiências. Consumer Behavior Review, 4(2), 128-145.
ISSN: 2526-7884

Editor: Prof. Dr. Marconi Freitas da Costa Journal's e-mail: cbr@ufpe.br
Evaluation: Double blind review

Received: 16 de fevereiro de 2020

Accepted: 8 de maio de 2020

\title{
PRODUÇÃO DE SENTIDOS NA INDÚSTRIA CULTURAL DA CERVEJA: ASPECTOS DO PROCESSO DISCURSIVO NAS AÇÕES DE MARKETING DE EXPERIÊNCIAS
}

\section{Production of Senses in the Cultural Beer Industry: Aspects of the discursive process in the experiences marketing actions}

\author{
Renato Augusto da Silva Monteiro ${ }^{1}$ \\ ORCID: https://orcid.org/0000-0002-8662-285X \\ E-mail: renatomonteiro.ufrj@gmail.com \\ Fábio Francisco de Araujo ${ }^{1}$ \\ ORCID: https://orcid.org/0000-0002-5581-5640 \\ E-mail: fabiofdearaujo@gmail.com
}

${ }^{1}$ Instituto de Nutrição Josué de Castro, Universidade Federal do Rio de Janeiro, Rio de Janeiro, Brasil

\begin{abstract}
Resumo
A cerveja é a bebida alcoólica mais consumida no Brasil. As estratégias discursivas das ações de marketing representaram, em grande medida, um importante valor simbólico socialmente construído para direcionar hábitos e preferências. Recentemente, a experiência é introduzida como a nova tendência nas práticas empresariais para fomento do consumo. Este estudo parte da teoria crítica com o objetivo de analisar o processo discursivo promovido no Centro de Experiência Cervejeira da Bohemia (CECB)
\end{abstract}

\begin{abstract}
Beer is the most consumed alcoholic beverage in Brazil. The discursive strategies of marketing actions represented largely an important symbolic value socially constructed to direct habits and preferences. Recently, the experience is introduced as the new trend in business practices to promote consumption. This study starts from the critical theory in order to analyze the discursive process realized at the Centro de Experiência Cervejeira da Bohemia (CECB) to understand the strategies for producing meaning in consumers. This descriptive interpretive study
\end{abstract}


para compreender as estratégias de produção de sentido junto aos consumidores. Tratou-se de um estudo interpretativo descritivo, que utiliza a análise sóciohistórica e a técnica de análise de discurso para interpretação de imagens, textos e vídeos das salas de exposição. Os resultados apontam para a construção de uma elaboração discursiva a partir da experiência da visitação para criação de significados sobre a cerveja e a marca Bohemia, que visam à produção e à manutenção de determinados hábitos de consumo.

Palavras-chave: Marketing de experiência, Discurso, Consumo, Bebidas alcoólicas, Cerveja. based on the socio-historical analysis and the speech analysis technique to interpretation images, texts and videos of the exhibition rooms. The results point to the construction of a discursive elaboration based on experience to develop meanings about beer and the Bohemia beer brand, that aim at driving and maintenance of consumption habits.

Keywords: Experience marketing, speech, consumption, alcoholic beverages, beer.

\section{INTRODUÇÃO}

A expectativa quanto às mudanças comportamentais dos consumidores em relação à interação com marcas, produtos e serviços marcaram significativamente o novo milênio. Entretanto, esse movimento teve seu início na década de 1980, com o estudo de Holbrook e Hirschman (1982) ao abordar os aspectos experienciais do consumo. Como pontuado por Vargo e Lusch (2004), a lógica dominante do paradigma centrado nos bens não era capaz de responder todas as especificidades do mercado de consumo e, nesse sentido, Schmitt (2001) destaca a importância de processos interacionais com ações que promovem experiências para gestão de marketing no mercado e no consumo. Como sublinhado por Araujo e Rocha (2019), observa-se uma mudança paradigmática nas estratégias de marketing, na qual se tira o olhar da entrega do bem ou do serviço e o transfere para o processo da relação e interação com o consumidor.

No mercado de bebidas se destaca o consumo de produtos e serviços que promovem ações de interação com o consumidor com apelo às relações e à sociabilidade. Segundo Monteiro \& Gouvêa (2016), a cerveja é a bebida alcoólica mais consumida no Brasil. Faz-se interessante compreender como se deu tal direcionamento popular ao produto cerveja, considerando o papel do marketing nesse processo (Cruz et al., 2014), visto que a cerveja não contava um apelo de consumo no século XIX (Marques, 2014). Para compreender melhor esse processo, entretanto, é preciso refletir as imagens sociais que representam o momento contemporâneo, no qual se inclui o mercado de consumo de massa e a lógica produtivista do sistema capitalista.

Este estudo parte da teoria crítica, considerando as contribuições de Adorno e Horkheimer (1985), teóricos da primeira geração da chamada Escola de Frankfurt, para refletir sobre o consumo das bebidas alcoólicas no Brasil a partir das práticas de marketing de experiência empregadas no Centro de Experiência Cervejeira da Bohemia (CECB), espaço conhecido como o museu da cerveja, localizado em Petrópolis, no estado do Rio de Janeiro. 0 artigo tem como objetivo analisar o processo discursivo promovido no CECB para compreender as estratégias de produção de sentido junto aos consumidores. Nesse sentido, o estudo se refere à análise da construção de uma elaboração discursiva de cunho ideológico que articula a lógica produtivista e a experiência da visitação no processo de significação, a fim de justificar o gosto e o hábito de consumo por cervejas especiais da marca Bohemia. Para isso, optou-se por realizar recortes sócio-históricos que possibilitassem observar de forma panorâmica a configuração de hábitos em torno do consumo da cerveja, o que nos leva a problematizar as práticas que incidem sobre o imaginário de consumo. 


\section{A Indústria de Cerveja e o Processo de Constituição do Gosto do Produto no Brasil}

A produção de cerveja atravessou as duas revoluções industriais, sendo uma das primeiras manufaturas a se beneficiar do aumento populacional das cidades. Antes dos tecidos, as cervejarias teriam se tornado a primeira indústria de consumo de massa da Inglaterra, passando a serem produzidas em larga escala, favorecida pela abundância do carvão como fonte energética. Os grandes produtores se diferenciavam dos pequenos, com a nova divisão do trabalho a segmentação de tarefas foi implementada nas unidades fabris. No final do século XIX, foram introduzidos o termômetro e os sistemas de refrigeração artificial, esse último atribuído a Carl Von Linde, tecnologias consideradas marcos no controle do processo produtivo de cerveja que substituiriam a provisão de gelo natural cara e insuficiente diante da crescente demanda da indústria de alimentos. Assim, a partir de 1870, as cervejarias industriais se difundem para países com pouca tradição cervejeira, como é o caso do Brasil, pois "com a refrigeração abriu-se a perspectiva de se produzir cerveja nos mercados consumidores e sob quaisquer condições ambientais, inclusive nos trópicos" (Marques, 2014, p. 29).

Uma das formas mais usuais de classificação de cervejas as divide basicamente entre duas "famílias" de acordo com o tipo de levedura utilizada. Na produção de cervejas de alta fermentação (Ale) atua, sob temperaturas entre $18^{\circ} \mathrm{C}$ a $22^{\circ} \mathrm{C}$, a levedura Saccharomyces cerevisiae, comumente utilizada para a fabricação de pão, de modo que ao longo da Antiguidade e Idade Média muito provavelmente existissem apenas essas cervejas (Venturini Filho, 2010; BJCP, 2015). As cervejas de baixa fermentação (Lager) surgem a partir do século XVI na Alemanha, sendo caracterizadas pela atuação da levedura Saccharomyces pastorianus, que atua sob temperaturas mais baixas, entre $7^{\circ} \mathrm{C}$ a $15^{\circ} \mathrm{C}$ (Beltramelli, 2012).

O sistema de classificação de cervejas norte-americano, o Beer Judge Certification Program (BJCP), serve de referência para classificação e categorização da cerveja a partir de um conjunto padronizado de descrição dos estilos. O BJCP foi criado para uso em competições homebrew, que nos EUA surgiram na segunda metade do século XX a partir das associações de cervejeiros artesanais mediante a prática de produção de cerveja em casa. O BJCP (2015) é utilizado como um guia para degustação de cervejas, de modo que as categorias e os estilos são descritos seguindo os seguintes critérios de avaliação: impressão geral, aroma, aparência, sabor, sensação de boca, história, ingredientes, comparação de estilos, estatística vital (unidades de cor, unidade de amargor (IBU), ABV (\%), unidade de álcool, OG - Original Gravity e FG - Final Gravity).

No Brasil, emergiu recentemente um novo Decreto Federal que trouxe mudança na classificação das cervejas no país. Trata-se do Decreto no. 9.902/2019, que altera o Decreto no . 6.871/2009, regulador da Lei $\mathrm{n}^{\circ}$. 8.918/1994, que dispõe sobre a padronização, a classificação, o registro, a inspeção, a produção e a fiscalização de bebidas. A legislação brasileira define a cerveja como "bebida resultante da fermentação, a partir da levedura cervejeira, do mosto de cevada malteada ou de extrato de malte, submetido previamente a um processo de cocção adicionado de lúpulo ou extrato de lúpulo, hipótese em que uma parte da cevada malteada ou do extrato de malte poderá ser substituída parcialmente por adjunto cervejeiro", conforme artigo 1o do Decreto no. 9.902/2019 e artigo 36 do Decreto no. 6.871/2009. 0 recente Decreto Federal atualiza a compreensão do que se entende como cerveja, ampliando o conceito ao considerar a inclusão de matérias-primas de origem animal na receita, tais como mel, lactose e chocolate. Anteriormente ao decreto, ao se acrescentar ingredientes de origem animal na produção, perdia-se o direito de uso do termo cerveja no produto, sendo classificado como uma "bebida alcoólica mista", o que perde o apelo de marketing no mercado. Este movimento buscou dar efetividade a uma Instrução Normativa feita pelo Ministério da Agricultura, Pecuária e Abastecimento (MAPA), que além de simplificar o registro do produto permitindo a inclusão de ingredientes de origem animal, determinou a padronização para a rotulagem.

De acordo com Yamamoto (2011), a cerveja é a bebida alcoólica mais consumida no Brasil (61\%), cujo consumo se encontra relativamente distribuído entre as classes, se sobressaindo nas classes B, C e D. Em uma comparação, sublinha a incidência de variáveis demográficas entre o consumo de cerveja e o de cachaça, estando o primeiro mais localizado nos domicílios urbanos, com famílias menos numerosas, cujos chefes possuem maior escolaridade. 0 consumo de cachaça tende a se localizar em domicílios fora dos centros urbanos, com chefes de família com menor escolaridade e 
menor poder aquisitivo. Conforme a renda aumenta, a cachaça passa a ser substituída pela cerveja, havendo ainda variações em função das regiões.

De acordo com o levantamento do setor de bebidas alcoólicas do BNDES (Cervieri Júnior et al., 2014), ao longo do século XX se consolidou no Brasil uma estrutura econômica caracterizada pelo oligopólio, em que grandes indústrias cervejeiras fazem elevados investimentos em marketing, na ampliação dos canais de distribuição e na capacidade instalada, de forma a garantir maior participação no mercado. 0 mercado de cervejas no Brasil se caracteriza pela acirrada rivalidade entre os fabricantes, existindo altas barreiras à entrada de novos competidores. No início do século XXI, observamos que quatro companhias responderam por cerca de $98 \%$ do volume total de cerveja produzida, se apresentando a divisão do mercado da seguinte forma: Ambev (67,9\%), Cervejaria Petrópolis (11,3\%), Brasil Kirin (10,8\%), Heineken (8,4\%) e outros $(1,6 \%)$.

Diante desse panorama, se faz necessário desnaturalizar o gosto pela cerveja como algo inato, mas resultado de intrincadas relações de poder que teriam contribuído para que a cerveja se tornasse a bebida alcoólica mais consumida no Brasil (Monteiro \& Gouvêa, 2016). As marcas produzidas pelas cervejarias industriais, descritas acima, configuram uma monocultura Lager, uma vez que $98 \%$ das cervejas comercializadas no país se referem a um tipo de cerveja que poderíamos classificar como standard american Lager (BJCP, 2015).

\section{A Indústria da Cerveja e o Fetiche da Marca: apontamentos da teoria crítica}

$\mathrm{Na}$ perspectiva da teoria critica, a indústria cultural é entendida por Adorno e Horkheimer como aquela destinada às massas, na qual participariam milhões de pessoas, atuando por meio de métodos de reprodução e de disseminação de bens padronizados para satisfação de necessidades iguais. A técnica conquistaria seu poder na sociedade, sendo exercida como forma de dominação legitimada pela racionalidade. Para os autores, na indústria cultural as distinções de preço entre os produtos teriam menos a ver com o conteúdo dos mesmos, do que com a utilidade que enceram para a classificação e computação de estatísticas de venda, criando uma hierarquia de qualidades. Assim, a distinção entre os produtos seria ilusória, "as vantagens e desvantagens que os conhecedores discutem servem apenas para perpetuar a ilusão da concorrência e da possibilidade de escolha" (1985, p.102).

Cruz et al. (2014) reconhecem a existência de estratégias promocionais de marketing, tal como a propaganda, que no contexto da indústria cultural produzem discursos informacionais voltados à comunicação das massas, tendo como objetivo específico o processo de significação cultural de bens e produtos. Esse tipo de estratégia não é nova na indústria de cerveja, pois como aponta Marques (2014) a partir da análise da propaganda da cervejaria Brahma nas primeiras décadas do século XX, em locais como o Jockey Club e o restaurante Assírio do Teatro Municipal, frequentados pela elite carioca, o patrocínio de eventos visava conferir visibilidade e fortalecer a posição da marca no cenário nacional. As cervejarias industriais foram as primeiras a destinar gastos importantes em marketing, sobretudo, na época do carnaval, buscando popularizar o produto por meio de signos direcionados às classes elitizadas:

A iconografia utilizada na sua propaganda está repleta de símbolos que remetem à tradição da indústria cervejeira europeia. 0 frade medieval, imagem que lembra os mosteiros onde, diz a tradição, fazia-se a melhor bebida da Europa; a estrela de seis pontas, para alguns, um símbolo da pureza da bebida, feita sem aditivos, e, para outros, um dos principais instrumentos de trabalho do mestre-cervejeiro naquela época, o densímetro. Algumas peças de propaganda mostram consumidores vestidos de modo sofisticado, a usufruir da beleza da baia da Guanabara nos anos da belle époque. (Marques, 2014: p. 147-148).

Quando se observa o panorama atual das cervejarias industriais no Brasil, caracterizado pela concentração oligopolista, cuja produção majoritária se refere a um tipo de cerveja (standard american lager), voltada ao consumo de massa, é possível identificar estratégias da indústria cultural. Com 
Produção de Sentidos na Indústria Cultural da Cerveja: Aspectos do processo discursivo nas ações de marketing de experiências

propagandas voltadas ao grande público enquanto um produto de massa, as cervejas pouco se diferenciam entre si pelo conteúdo, o que corresponde à existência de uma ilusão de forma e a de uma falsa liberdade de escolha (Marques, 2014; Fontanelle, 2013). Ainda que seja possível notar movimentos de tipificação, como o da cerveja premium, seriam especificações mais baseadas em critérios mercadológicos do que em características intrínsecas aos produtos, não coincidindo, por exemplo, com as classificações adotadas internacionalmente pelo BJCP (2015). Isso ocorre porque "o que motiva as grandes companhias brasileiras a ingressar nesse nicho de mercado é a possibilidade de auferir melhores margens de lucro e conquistar maior fidelidade às marcas vendidas" (Rosa, Cosenza e Leão, 2006, p. 132).

Como previam Adorno e Horkheimer (1985, p. 108), com o desenvolvimento e a padronização da técnica, a indústria cultural teria excluído o amadorismo por meio de um processo de repetição no aperfeiçoamento da produção em massa. Assim, seriam reforçados estereótipos reconhecidos dentro de ideologias na medida em que os conteúdos possam corresponder às identidades criadas, ainda que se refiram a uma "pseudo-individualidade", pois "a indústria cultural acaba por colocar a imitação como algo absoluto. Reduzida ao estilo, ela trai seu segredo, a obediência à hierarquia social".

A partir do século XX, a padronização dos meios de produção tornou os produtos semelhantes, passando a se diferenciarem da concorrência cada vez mais por meio das marcas, dimensão imaterial dos produtos, tal como ocorre na indústria da cerveja com elevados investimentos em propaganda (Silva, 2012). Fontenelle (2013) analisou a trajetória do McDonalds propondo uma leitura da indústria cultural no contexto da disputa mercadológica. 0 produto da indústria cultural reduziria o prazer que promete ao fetiche da mercadoria, de modo que os altos investimentos em propaganda acabariam retornando às grandes corporações, como no caso das cervejarias industriais. Nesse caso, o poder de fixação de preços aconteceria via a construção de marcas, o que demandaria altos investimentos em propaganda para ingressar e permanecer no setor. Desse modo, como previam Adorno e Horkheimer (1985), a propaganda se torna tão essencial que o abandono dessa prática incorreria em infração, pois o próprio sistema obrigaria à utilização da técnica promocional a todo produto da indústria cultural. Assim, a propaganda aciona tudo o que seja portador e gerador de significados que expressem valores e comportamentos com o objetivo de efetivar o consumo, entendido como um ato essencialmente cultural, pois não acontecem sem um significado ou sentido.

Assim, as marcas teriam um peso central na determinação do valor de mercado das empresas, podendo ser avaliadas de acordo com uma metodologia baseada em aspectos mercadológicos (Aaker, 1997). Nessa direção, observa-se o estudo de Silva (2012) que analisou as propagandas de cerveja das marcas Itaipava e Skol, de modo que a Skol lançou, em 2011, a campanha Chegou Skol $360^{\circ}$ graus, fruto de três anos de pesquisa, que levaria ao mercado uma cerveja que "não estufa" e que "desce redondo".

No ranking da Interbrand (2019), que classifica as 25 marcas mais valiosas do mercado brasileiro, estão na primeira e na segunda posição os bancos Itaú e Bradesco, em terceiro lugar a marca de cerveja Skol, em quarto e em sétimo as cervejas Brahma e Antarctica. Todas essas marcas de cerveja pertencem à Ambev, o que demonstra seu alto valor de mercado, estando as marcas de cerveja Skol e Brahma atrás apenas de importantes agentes financeiros como os bancos Itaú e Bradesco. Entretanto, essas marcas de cerveja são do mesmo estilo (standard american lager), ao passo que existem mais de 200 estilos de cerveja descritos pelo BJCP (2015). Dessa forma, considera-se a existência de uma monocultura lager pela pouca variedade de estilos que configuram o mercado brasileiro, cuja diferença se apresenta mais em função das marcas do que das características de estilo, ingredientes e leveduras, motivo pelo qual a propaganda possui um lugar essencial na produção da diferença, que se reflete na escolha do consumidor. Beltramelli (2012) entende essa monotonia como "ditadura lager".

\section{Estratégias de Marketing de Experiência}

Holbrook e Hirschman (1982) foram pioneiros no estudo do impacto da experiência sobre os hábitos e as práticas de consumo. Para esses autores, o ato de comprar é mais complexo do que apenas ir a lojas em busca de produtos (Griffith, 2003). A experiência da compra deve satisfazer além de 
atributos utilitários, os atributos emocionais e multissensoriais chamados de experiências hedônicas (Schmitt, 2001). Nessa linha, Baudrillard (2008) pontua que o consumo ultrapassa as questões apenas utilitárias, estando mais relacionado aos significados que este consumo pode trazer ao indivíduo.

A emergência de estudos sobre a cultura hedônica do consumo reflete as mudanças econômicas e sociais vividas no final do século passado. Nesse contexto, as ações que promovem experiências surgem como estratégias de diferenciação de produtos, serviços e marcas em resposta ao caminho de massificação que as estratégicas de vendas assumiram no processo de disponibilização dos produtos e serviços. Por essa razão que Pine II e Gilmore (1998) chamaram a era que vivemos de "economia da experiência".

Esse contexto, somado ao domínio da tecnologia da informação, à ascensão da cultura do entretenimento (Araujo e Chauvel, 2012) e, no campo do marketing, ao surgimento do discurso da supremacia das marcas, tornou-se terreno fértil para o nascimento do conceito de marketing de experiências (Schmitt, 2001). Diferente do marketing tradicional, focado nas características e benefícios dos produtos, o marketing de experiências volta-se para as experiências proporcionadas em situações de consumo, não ficando restritas somente à objetivos e bens de consumo, mas também às práticas socioculturais de consumo realizadas por grupos e subculturas de consumo (Araujo, Turano, e Vieira, 2019; Matsunobu, 2018; Moura \& Araujo, 2020; Silva \& Barbosa, 2018).

Schmitt (2001) propõe que as associações sensoriais, afetivas e cognitivas dos consumidores com as marcas podem resultar em experiências memoráveis e compensadoras. 0 autor elabora a abordagem do marketing de experiências, defendendo que os consumidores esperam que os produtos e serviços estimulem os seus sentidos e mexam com suas emoções, traduzindo seus estilos de vida.

Avançando no debate, Schmitt, Brakus \& Zarantonello (2014) empreenderam um estudo no qual os resultados apontam que as experiências que ocorrem durante o uso e consumo de produtos de marca podem representar estímulos mais fortes para a compra repetida e recomendações boca a boca, além de recomendações on-line, pois a experiência que fica na memória dos indivíduos tende a gerar uma resposta positiva do consumidor.

Nessa perspectiva, Ding et al. (2010) e Meyer e Schwager (2007) seguem na direção de que a experiência é a interpretação e sentimento pessoal do processo de serviço, da interação e envolvimento durante esse processo por meio de uma série de pontos de contato. Para Vargo e Lusch (2004), a experiência é percebida puramente a partir do ponto de vista individual, sendo inerentemente pessoal, existindo apenas na mente do cliente. É oportuno observar o crescente interesse entre os pesquisadores da área sobre temas relacionados ao marketing de experiências, questionando os paradigmas tradicionais do marketing, como pode ser observado em estudos recentes (Araujo \& Rocha, 2016; Araujo et al., 2019; Azambuja \& Bichueti, 2016; Brakus et al., 2009; Brito et al., 2017; Lira et al., 2020; Mhlanga \& Tichaawa, 2017; Schmitt, Brakus \& Zarantonello, 2015; Shamim \& Butt, 2013; Scussel, 2019; Silva \& Barbosa, 2018; entre outros). Percebe-se, assim, que o conceito de experiência deve ser percebido como uma variável relevante nas ações promocionais das empresas no mercado (Holbrook, 2000).

\section{MÉTODO}

Para etapa empírica deste estudo, parte-se de uma empresa que atua no mercado da indústria de cerveja e que possui ação de estratégia de marketing de experiência. A partir desse cenário, definiuse o caso escolhido: análise da visitação promovida aos consumidores no CECB para compreender o processo discursivo e, assim, buscar identificar as estratégias de produção de sentido no espaço estudado a partir da ação de marketing aplicada. Vale lembrar que a marca Bohemia pertence à Ambev, em que pese o mercado de bebidas alcoólicas se tratar de um setor muito competitivo, a empresa é considerada líder nesse ramo no Brasil. A escolha do CECB se deu por considerar ser este um espaço de entretenimento com sucesso de público em que são utilizadas estratégias do marketing de experiência, possuindo mais de 11.000 avaliações no TripAdvisor, (2020), sendo que cerca de 90\% dos consumidores classificam a experiência no local como excelente (63\%) e muito bom (27\%).

Buscou-se problematizar os sentidos produzidos para o consumidor de cerveja em uma visitação, que ocorre ao longo de um percurso de experiência por meio de um tour cervejeiro. 0 
Produção de Sentidos na Indústria Cultural da Cerveja: Aspectos do processo discursivo nas ações de marketing de experiências

objetivo foi problematizar a produção de sentidos sobre cerveja em uma sala de exposição, adotando a teoria crítica e o marketing de experiência. Trata-se de um estudo descritivo e interpretativo no qual a coleta de dados considerou a pesquisa de campo, notadamente a observação, realizada durante as visitações no CECB (Alcadipani \& Hodgson, 2009). Inicialmente se realizou uma leitura panorâmica dos dados da pesquisa de campo que se iniciou em 2015, mas ocorreu, sobretudo durante os meses de janeiro, fevereiro e março de 2016, realizada por um dos autores.

Por razões de conveniência e maior frequência de visitantes, optou-se por realizar as visitas de sexta-feira a domingo, sendo realizadas 66 visitas, ou seja, voltas completas pelo tour, o qual levava em média de uma hora a uma hora e meia, sendo utilizado para o registro da pesquisa uma câmera fotográfica e um caderno de campo para as anotações (Elliot \& Jankel-Elliot, 2003; Strauss \& Corbin, 2008). As visitas se encerraram em meados de março, quando se entendeu ocorrer a saturação dos dados colhidos. A coleta recaiu, portanto, sobre as exposições no que se refere ao conteúdo de textos e imagens, sendo o contato com visitantes e monitores restrito às observações de campo que levassem a uma visão panorâmica do conjunto, contribuindo para compreensão do contexto. Para a constituição dos dados da pesquisa, transcreveu-se os textos de painéis, aparatos e vídeos, bem como imagens por meio de fotografias de trechos, ambientação ou aparatos das salas de exposição.

Estruturou-se os procedimentos de pesquisa assumindo uma perspectiva ampla sobre os textos colhidos, reconhecendo-os ao mesmo tempo como produto e articulador da atividade humana, como algo carregado de sentidos que, por sua vez, são compreendidos a partir de seus respectivos contextos de produção e interação social. A análise da linguagem deve ser tomada em consideração às estruturas sociais historicamente constituídas, porém, sem deixar de considerar o objeto textual em sua própria natureza (Habermas, 1989). 0 tratamento dos dados colhidos foi realizado a partir de duas etapas fundamentais, a saber: análise sócio-histórica e técnica de análise de discurso. Primeiramente, foi realizada a análise do contexto sócio-histórico de produção dos discursos em todas as formas apresentadas aos consumidores durante a experiência, que visa à análise de formas simbólicas a partir de seu contexto social e histórico de produção e reprodução. Segundo Thompson (2000), a análise sócio-histórica reconstitui o caráter diacrônico das formas simbólicas, delimitando seu escopo de significação em determinado contexto espaço-temporal e por determinadas condições sociais de produção desses significados. No caso da ação de marketing de experiência em análise, o discurso enquanto prática de ação comunicativa foi contextualizado a partir da trajetória dos consumidores durante a experiência da visitação e suas práticas de interação comunicativas durante esse processo.

Foi utilizada a técnica de análise do discurso (Carneiro, 2011; Strauss \& Corbin, 2008; Thompson, 1997), considerados recursos importantes no processo de construção da significação do produto cerveja a partir da ação de experiência proposta pela Bohemia. A escolha de documentos que constituíram o corpus se deu em função de um recorte a partir das salas de exposição, entendidas como unidades de significação. A preparação do material para a análise interpretativa mais profunda e refinada do conteúdo se processou a partir de dados advindos da ambientação, fotos, imagens, vídeos, aparatos da sala de exposição e caderno de campo. Segundo Strauss e Corbin (2008), o objetivo delimitado deve (1) iniciar o processo de análise dos significados atribuídos às mensagens a partir do discurso obtidos nos objetos, filmes e fala dos monitores da visitação; (2) desenvolver um conjunto de características iniciais e temas a partir dos discursos presentes nas observações, fotos, imagens, vídeos, aparatos da sala de exposição, conversas informais com monitores e consumidores visitantes; (3) releitura do diário de campo e reanálise do material reunido para confirmação das características identificadas; (4) selecionar e identificar novas características e temas que surgiram do campo a partir da exercício de comparação constante indicado por Strauss e Corbin (2008); (5) verificar novamente os dados com base nas premissas do marketing de experiência para identificar e confirmar o processo criação de significados por meio das práticas de discursivas presentes na sala analisada durante a visitação.

A maioria dos procedimentos de análise se organizam ao redor da categorização, que pode ser entendida como uma operação de classificação de elementos constitutivos de um conjunto por diferenciação e, em seguida, por reagrupamento segundo a analogia, com critérios previamente definidos. Nesse processo, os elementos são isolados e reagrupados, tendo como objetivo fornecer 
uma representação simplificada dos dados brutos (Strauss \& Corbin, 2008). Entretanto, a operação de isolamento e reagrupamento das categorias encontrou limitações nesta pesquisa, uma vez que se optou por contemplar a análise dos dados mediante a sequência em que se apresentavam as salas do percurso. Isso se deve porque se considerou que cada sala corresponde a uma unidade de pensamento que se articula com o todo na construção de dada narrativa do discurso sistematicamente produzido (Carneiro, 2011; Bardin, 2011). Assim, cada sala aberta à visitação foi entendida como uma unidade de significação, tendo o presente estudo se dedicado à sala Saga da Cerveja, que representa no trajeto, por meio de aparatos interativos, a história da cerveja desde à Antiguidade, passando pela Idade Média, Idade Moderna até a Idade Contemporânea.

Por fim, considera-se a natureza qualitativa do estudo como uma das limitações que se refere à intenção de generalização ou de extrapolação dos resultados. Pelo caráter exploratório, busca-se contribuir, a partir de uma análise mediada sob outra perspectiva paradigmática, a crítica, permitindo o avanço do conhecimento e o debate sobre o referido tema para o marketing de experiências.

\section{ANÁLISE DOS RESULTADOS}

Esta seção apresenta e discute os resultados da pesquisa de campo, apresentando o processo de significação do marketing de experiências na ação promovida pelo CECB durante o período de visitação. Como informado na seção anterior, considerou-se o percurso de visitação como uma unidade de significação. Para este artigo, dedica-se um debate sobre o marketing de experiências na sala Saga da Cerveja.

\section{(1) Marketing de Experiências na sala Saga da Cerveja}

Algumas pistas sobre o que seja cerveja aparecem na primeira sala intitulada Saga da Cerveja. 0 termo saga se aproxima da ideia de antigas narrativas, histórias, contos, o que, no espaço, se refere à construção de um discurso através do tempo dando à cerveja o caráter lendário ou heroico. Não seria, porém, uma saga qualquer, mas uma saga da cerveja, que parte de um locutor autorizado a contar a história da cerveja, o que se diferencia, por exemplo, de contar uma história sobre a cerveja, opção que colocaria em relevo a existência de uma construção discursiva marcada e situada em dado contexto.

Nessa sala, o visitante pode se mover livremente na ordem que desejar, ainda que o percurso se baseie em uma perspectiva temporal linear, pois se organiza em torno de linhas do tempo que dizem respeito a trechos que destacam datas importantes de cada período. Os períodos eram representados por meio de uma museografia que dividia a sala da seguinte forma: Pré-história, Idade Antiga, Idade Média, Idade Moderna e Idade Contemporânea. Os aparatos se situavam em ambos os lados do percurso, dando a impressão de se estar imerso em outros mundos, como em uma taverna medieval (Idade Média). A sala possuía um ligeiro aclive que valorizava o efeito do piso como se escorresse um líquido de cerveja sob os pés. Em tom amarelo claro simulava um líquido borbulhante que parecia lembrar o efeito do gás dióxido de carbono que confere a carbonatação na cerveja. Esse efeito chamava a atenção dos visitantes, em especial das crianças, que comumente tentavam pisar sobre as borbulhas que pareciam estourar em diferentes pontos. Uma visão panorâmica da entrada da sala pode ser observada na fotografia da Figura 1.

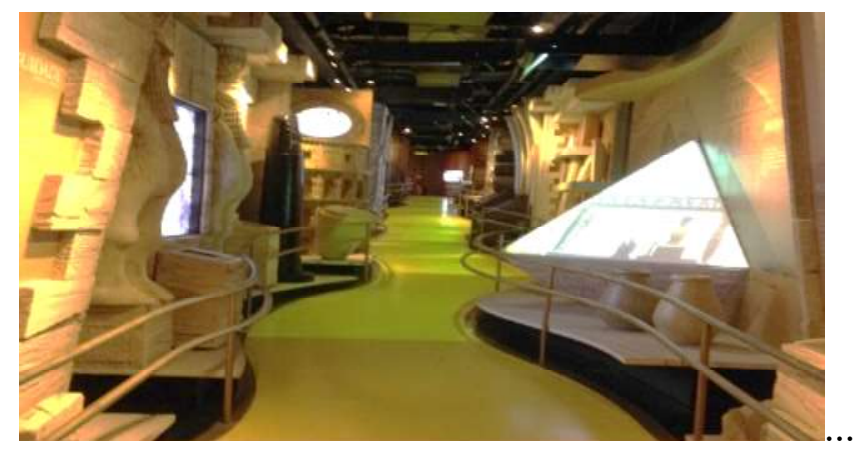

Fonte: Acervo dos Pesquisadores

Figura 1. Entrada da Sala Saga da Cerveja 
Produção de Sentidos na Indústria Cultural da Cerveja: Aspectos do processo discursivo nas ações de marketing de experiências

Além do investimento em aparatos interativos, como quiosques multimídia, computadores com telas touch screen, que possibilitavam ao visitante aprofundar o conhecimento sobre o tema, buscando destacar a profusão de imagens que recriavam realidades a partir de objetos substitutos, que remetem à ideia de objetos originais por meio de uma museografia. Vale situar que alguns aparatos apresentavam vídeos com recurso sonoro, como para apresentar um mito ou criar um burburinho que se assemelhasse ao de uma taverna. No trecho a seguir, destaca-se a ideia da cerveja enquanto ouro líquido, que aparece duas vezes no painel que introduzia a sala:

Uma viagem pela alquimia do ouro líquido. Vamos retroceder 8.000 anos na história da humanidade e conhecer a origem e a evolução da cerveja nas principais civilizações, e como ela influenciou os povos em diversas áreas do conhecimento. Esta história começou com o sopro dourado, uma lenda recheada de magia e inspirada no sopro de uma antiga deusa, que revelou ao mundo o ouro líquido. Através dele você vai percorrer as grandes eras da civilização antiga, medieval, moderna e contemporânea, descobrindo a saga da cerveja paralelamente à evolução humana. Divirta-se! (Painel da entrada Sala Saga da Cerveja).

Nota-se que o termo ouro se refere a um material visto socialmente como nobre, relacionado às joias de alto valor, sendo a cerveja tomada como um ouro líquido na narrativa. Assim, fica clara a associação da cerveja como uma bebida de valor, o que se estende ao seu consumidor, de modo que nessa experiência o marketing atuava valorizando a bebida e, logo, o seu bebedor. Ocorre assim a valorização da cerveja enquanto uma bebida de mais elevado valor agregado quando comparada às demais, em especial ao vinho, que também é uma bebida fermentada produzida desde as antigas civilizações. Entretanto, na Grécia Antiga eram vistos como mal bebedores os povos que consumiam cerveja, sendo o vinho cultuado como símbolo de civilização. Ao longo de toda Idade Média, o vinho era mais procurado e valorizado do que a cerveja (Flandrin, 2015). Essa questão leva Bamforth (2008) a se debruçar em uma comparação histórica, tecnológica e social entre cerveja e vinho, buscando entender o lugar social de destaque dado ao vinho, comumente associado ao glamour e à existência de um ritual próprio, enquanto a cerveja seria vista como uma bebida ordinária e menos nobre. Em relação à matéria-prima, considera que o vinho requer mais cuidados no que refere ao cultivo da uva, quando comparada ao cultivo de grãos, de modo que o próprio conceito de terroir seria pouco comum na produção de cereais, matéria-prima da cerveja.

Sem esgotar o mérito da discussão que pode suscitar um debate em torno do lugar social dado a cerveja em relação a outras bebidas alcoólicas, interessa sinalizar que as estratégias de marketing nessa sala buscavam construir uma narrativa segundo a qual a cerveja seria uma bebida diferenciada, que como o ouro não perde suas características a depender do meio. No discurso da sala, a história da cerveja teria começado com um sopro dourado de uma antiga deusa, o que aponta para a existência de uma origem envolta em certa dimensão onírica. Além disso, o trecho se dirige a um "você", ou seja, apresenta-se como um chamado, um convite para que o visitante descubra algo, o que pressupõe a participação ou a interação por meio da experiência ao longo do percurso.

Tendo a produção de cerveja origem na Pré-história, a exposição dessa sala abordava os povos da Mesopotâmia (sumérios e babilônicos): "os principais povos da Mesopotâmia, sumérios e babilônios, criaram as duas mais belas lendas que ilustram a história da cerveja no mundo antigo", de modo que "aos sumérios é creditada a descoberta da cerveja. Segundo a lenda, surgiu com o sopro mágico, uma dádiva da deusa Ninkasi, que transformou uma simples mistura de água e cevada no líquido dourado de sabor agradável". Pode-se sinalizar que tanto aqui como ao longo do percurso são retomados termos como "sopro mágico", "dádiva da deusa", "líquido dourado", o que diz respeito à intenção de dar à cerveja uma dimensão valorativa de origem histórica emoldurada pela magia. Contribui também para pensar que os usos das bebidas alcoólicas fazem parte da cultura desde épocas remotas. 
A passagem da Antiguidade para a Idade Média parece ter sido feita por meio dos romanos, de modo que estes, tendo herdado o conhecimento cervejeiro dos egípcios, teriam se tornado difusores da cerveja, como na narrativa contada na sala:

Conquistadores e desbravadores do mundo antigo, os romanos herdaram o conhecimento cervejeiro dos egípcios, e a partir daí tornaram-se os responsáveis por sua difusão. Da mesma forma que levaram a bebida aos novos territórios conquistados, também trariam ao conhecimento de Roma as novas fórmulas e receitas aprendidas com outros povos. (Painel do trecho dos romanos, Sala Saga da Cerveja).

Dessa forma, a cerveja seria a bebida difundida pelos romanos na Europa, o que se revela, portanto, como uma estratégia de marketing que busca valorizar a experiência do lugar, gerando certo encantamento que relacionava a cerveja a povos tidos como conquistadores. A cerveja colocada ao lado dos difusores do vinho (romanos) atua na produção do discurso em sentido contrário ao imaginário social, no qual a cerveja ocuparia um lugar valorativo secundário em relação ao vinho. Essa inversão remete às estratégias de propaganda adotadas pela Marlboro na década de 1950. Segundo Fontanelle (2013), os cigarros de filtro eram considerados afeminados nos EUA, de modo que a marca Marlboro buscaria transmitir em suas propagandas uma imagem contrária a essa construção imaginária, optando por um tipo masculinizado de homem, um cowboy, que se tornou o herói, valente e solitário em meio a uma imagem do país no esplendor de suas possibilidades. No mesmo sentido, ao colocar os romanos como difusores da cerveja na Europa, o que representa uma apropriação histórica questionável, leva ao apagamento dos usos da cerveja associada aos povos da Europa nórdica e central (Fernandes, 2004).

Apesar do discurso de associação da cerveja aos romanos, do ponto de vista histórico não seriam os romanos os povos conhecidos como os difusores da cerveja na Europa. A bebida que era produzida e cultuada, sobretudo, pelos povos da Europa nórdica e central. Já os romanos eram grandes produtores e apreciados do vinho, levando o cultivo da uva a diversas regiões de seu império (Fernandes, 2004). Como aponta Montanari (2015), somente com o tempo, a cerveja deixaria de ser um líquido denso para se tornar um líquido transparente e aromatizado pelo lúpulo, ascendendo aos poucos em prestígio social. Entretanto, apesar das fontes históricas sobre o assunto, nesta sala, os romanos são apresentados como os difusores da cerveja, como observado na imagem a seguir:

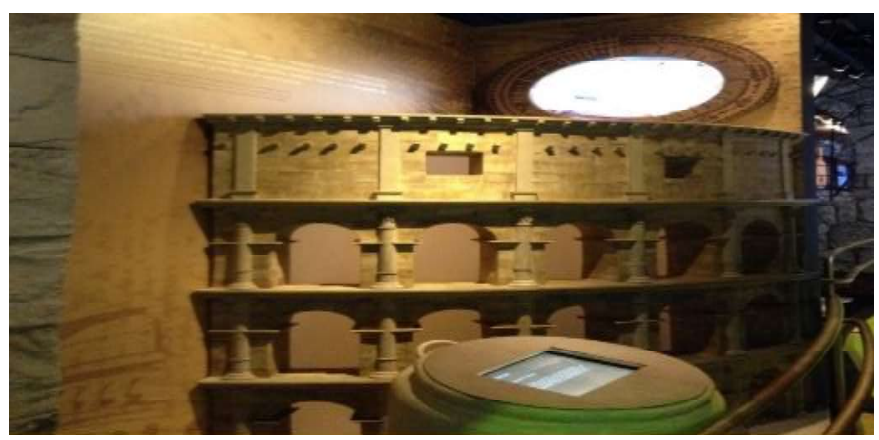

Fonte: Acervo dos Pesquisadores

Figura 2. A cerveja e os romanos

0 vídeo apresentado nesse aparato tem como imagem de fundo um mapa da Europa antiga, onde era simulado o percurso de conquista dos romanos, que partiriam de Roma com o ouro líquido, difundindo-o em diferentes pontos do mapa que se referem às regiões conquistadas. Considerando que as estratégias de marketing de experiências se voltam para as experiências proporcionadas em situações que envolva a marca ou o produto (Schmitt, Brakus \& Zarantonello, 2014), a associação da cerveja com os romanos se apresenta como uma estratégia para ingressar no imaginário dos 
Produção de Sentidos na Indústria Cultural da Cerveja: Aspectos do processo discursivo nas ações de marketing de experiências

participantes da experiência que, ao revés da história, obtém uma narrativa na qual os romanos ficaram encantados pela diversidade de cereais para a produção de cerveja, aderindo assim àquela que se tornaria uma bebida popular:

Os romanos são grandes aprendizes dos egípcios no preparo de cerveja. Encantados pela diversidade de cereais que podem adicionar ao preparo, diferente do vinho que necessita de muitos cuidados, os romanos aderem à cerveja e a tornam uma bebida de muita popularidade. (Texto do quiosque, trecho dos romanos, Sala Saga da Cerveja).

Em suma, o discurso de marketing se anteciparia ao visitante produzindo a inversão de sentidos contrários ao imaginário social, fazendo com que a cerveja passe a ser considera socialmente uma bebida superior ao vinho, o que se revela como estratégia de apropriação histórica permeada de contradições, que visa a conferir glamour à cerveja e distinção ao consumidor da bebida.

o quiosque intitulado "Livro do conhecimento cervejeiro" iniciava com a seguinte frase: "eu sou um monge, um estudioso, um alquimista, um profundo conhecedor da arte cervejeira. Escrevo estas páginas para deixar às futuras gerações o conhecimento cervejeiro que reuni através de anos de pesquisa". Assim, a cerveja adentraria nos mosteiros medievais passando a ser produzida mediante um conhecimento tido como mais acurado, como nesse trecho do painel: "na Idade Média, o conhecimento da escrita, de domínio quase exclusivo dos monges, dá aos mosteiros o monopólio da produção cervejeira. Dentro desse ambiente de disciplina e perfeição, a cerveja é produzida conforme a alquimia dos cervejeiros da época". Este quiosque se destinava aos santos cervejeiros, as estratégias de marketing proporcionadas pela experiência visavam buscava ao visitante a possibilidade de acessar informações referentes às datas de celebração dos santos, sendo cada santo relacionado a uma cerveja específica.

$\mathrm{Na}$ tela o visitante podia escolher o santo com o qual se identificava e aprofundar as informações sobre o mesmo, como a data em que se celebra o santo e sua relação com a cerveja. Alguns santos são considerados padroeiros da cerveja de cidades ou regiões situadas na Europa como Áustria, Bohemia, Bélgica, Escócia e França. Tomando um dos santos como exemplo, pode-se observar que São Columbano "fundou vários mosteiros pela Europa, criando as bases para as atuais cervejarias modernas. Por sua importância para a cultura cervejeira, é homenageado até os dias de hoje".

0 monge é apresentado como um "estudioso", um "alquimista", um "profundo conhecedor da arte cervejeira", que teria deixado o conhecimento acumulado de suas pesquisas, de modo que esse conhecimento seria herdado e assegurado as "futuras gerações". Aqui, observa-se a estratégia de valorização do conhecimento sobre a produção da cerveja enquanto uma bebida que não é feita de qualquer maneira, mas nos mosteiros, espaços de guarda e divulgação do conhecimento no período medieval, sendo os "metres cervejeiros" dos mosteiros os "guardiões dos segredos do líquido doutorado", cuja missão seria aperfeiçoar a cerveja e transmitir o conhecimento de uma "alquimia milenar" as gerações. Assim, a partir da experiência, a narrativa buscava reforçar a ideia da cerveja enquanto uma bebida herdeira de destacada tradição.

\section{(2) O Processo de Produção da Saga da Cerveja a partir da Experiência da Visitação}

Almeida e Rocha (2008) utilizam o conceito de pátina a fim de analisar seus efeitos nas garrafas, rótulos e propagandas em cinco bebidas alcoólicas: Grant (uísque), Ypióca (cachaça), Dom José (vinho), Frangelico (licor) e da cerveja Bohemia Pilsen. De acordo com McCracken (2003), o efeito de pátina não diz respeito à pátina em si, mas a uma propriedade simbólica da cultura material que objetiva autenticar o status da marca. A pátina não seria uma propriedade física dos objetos, mas uma representação dos sinais da passagem do tempo inscrita nos objetos, tratando-se de uma propriedade simbólica que atua com propósitos de distinção e tradição. Assim, embora uma garrafa de vinho do Porto não tenha cem anos, o efeito da ilusão da pátina marcaria a passagem do tempo por meio de desenhos, fotografias, relatos, histórias etc. 
Esse conceito pode ser aplicado às estratégias de marketing de experiência, como as utilizadas nesse quiosque, no que se refere à criação de uma cenografia de um tempo passado, recorrendo a uma das características do efeito de pátina por meio do acionamento da história de personagens reais, de um local ou de uma empresa, buscando gerar o interesse e a ligação do consumidor com a marca. Uma marca de cerveja que se utiliza dessa estratégia são as cervejas trapistas, agregando valor ao produto por meio da produção de sentidos simbólicos da marca, remetendo à ideia de tradição, como uma cerveja cuja receita e modo de produção resistiria a passagem do tempo. Nesse quiosque, as cervejas trapistas são abordadas como aquelas produzidas no "mosteiro de Notre-Dame de La Trappe", onde "vivem monges conhecidos como Trapistas. Eles produzem uma cerveja de alta qualidade que é o resultado de uma alquimia perfeita".

Outro espaço que investe no efeito de pátina se refere ao quiosque da taverna medieval: "é nas tavernas e na vida cotidiana que a cerveja encontra o seu grande mercado consumidor, sempre como o líquido que alegrava e brindava as celebrações da idade medieval". Quando comparada aos bares e restaurantes modernos, bem como as publics houses da era vitoriana, as tavernas medievais estariam mais próximas de uma hospitalidade "pura" (Schivelbusch, 1992), portanto, menos mercadológica. Entretanto, o quiosque coloca em relevo a existência de uma relação comercial no contexto de um "mercado consumidor", fazendo com que o visitante pudesse nessa experiência se sentir o consumidor da taverna, produzindo uma percepção de continuidade temporal marcada pela tradição para o consumo. A estratégia da experiência articulada à tradição é comumente utilizada em diferentes contextos, ainda que os consumidores não se apercebam diretamente, tais como se observou nos achados de Araujo et al. (2019) e Matsunobu (2018). No caso do quiosque, quando o visitante se aproximava da taverna era possível ouvir um som que dava a impressão de um burburinho, como se existissem pessoas conversando e bebendo. As estratégias de marketing aqui utilizadas produziriam sentidos relacionados a um ambiente no qual a experiência de estar em uma taverna medieval seria recriada, investindo em um sentido de proximidade, pois qualquer visitante poderia associar o burburinho a uma experiência de sua vida cotidiana ao estar em um bar ou em um restaurante.

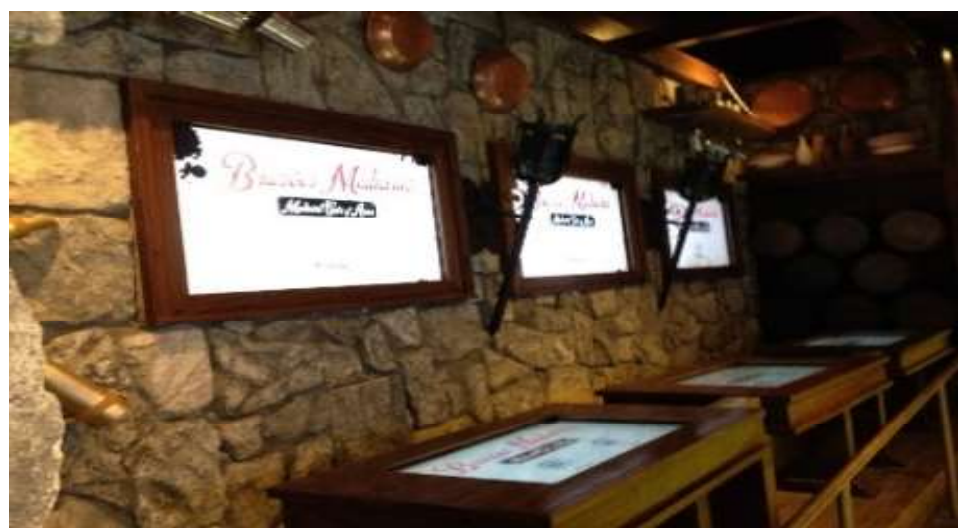

Fonte: Acervo dos Pesquisadores

Figura 3. Trecho das tavernas e dos brasões medievais

A interação com o aparato era possível a partir do toque do visitante na tela da mesa que gerava uma imagem reproduzida na tela da parede, sendo o cenário composto por objetos como tochas, panelas e canecos. Uma cenografia que buscava remeter a uma taverna medieval, recriando um espaço em que o consumidor se sentisse imerso na experiência. Como descreve o aparato intitulado "brasões medievais", as tavernas criavam seus brasões a fim de serem identificadas às cervejas vendidas no local: "Na Idade Média, os cavaleiros usavam os brasões para serem identificados com rapidez pelos seus companheiros". Assim, os brasões ganharam um significado mais simbólico: indicar nobreza e a qual nível da corte pertencia.

Entretanto, o discurso sobre a nobreza dos brasões medievais associada às tavernas possuia uma contradição, uma vez que as tavernas eram desde a origem romana (tabernae e propinae) 

experiências

espaços públicos frequentados pela plebe, onde era possível comer e beber, recuperando por meio delas o acesso aos valores dos quais se era excluído, como o convívio dos banquetes da elite romana. Segundo Montanari (2015), o termo tabernae pode ser entendido como uma loja de bebidas onde também é possível se alimentar, ao passo que popinae estaria associado à ideia de taberna ou bodega, onde são servidas refeições acompanhadas de bebidas, sendo os alimentos comumente cozidos em grandes caldeirões que forneciam comida quente.

Grande parte das informações que se dispõe sobre esses lugares provém de textos de autores das classes superiores, de textos nos quais as tavernas das cidades medievais eram vistas como locais mal afamados, sendo esnobados como espaços sebosos e enfumaçados, onde se poderia encontrar comida quente, sopas e cozidos. Dessa forma, estar em uma taverna medieval não significava possuir uma origem nobre, como se busca significar no aparato dos brasões medievais. Assim, essa estratégia de marketing buscava conferir status de nobreza à cerveja, sentido que se estende ao imaginário do visitante por meio da experiência e do entretenimento (Holbrook, 2000), ao sugerir que este forme seu próprio brasão no aparato. Acessando com o toque a tela na mesa da taverna, o visitante poderia, então, escolher entre três formatos de brasões a partir de três maneiras de dividi-lo. Em seguida, a escolha se dava entre três cores "que tenham mais a ver com sua personalidade", tal como a seguir:

Vermelho (Gules) e Ouro (Or): força militar. Dependendo da situação é capaz de ser muito generoso com todos. Azul (Azure) e Prata (Argent): sincero e adepto da paz. Utiliza a força a serviço da lealdade ao rei e aos companheiros. Verde (Vert) Ouro (Or): generoso, cultiva a esperança e é leal ao amor (Mesa dos brasões medievais, Sala Saga da cerveja).

Dessa forma, a escolha giraria entre o "vermelho" e "ouro" relacionado à "força militar", o "azul" e "prata" ao "sincero" e a "paz", o "verde" e o "ouro" ao "generoso", que "cultiva a esperança e é leal ao amor". 0 aparato recorria a estratégia de gerar sentidos relacionados à personalidade do visitante, potencial consumidor, investindo em uma relação de identidade e de personalização da experiência na taverna. Ao final, se deveria optar por um animal, que aparece no centro do brasão relacionado a valores, tais como: o "leão, muita coragem e força"; "o dragão, que é muito valente, tem o espírito da defesa sempre presente" e o "grifo, grande soldado que está sempre vigilante para defender os seus valores". Finalizadas as escolhas, surgia na tela um brasão com espaço para que seja inserida uma palavra, conforme se vê a seguir:

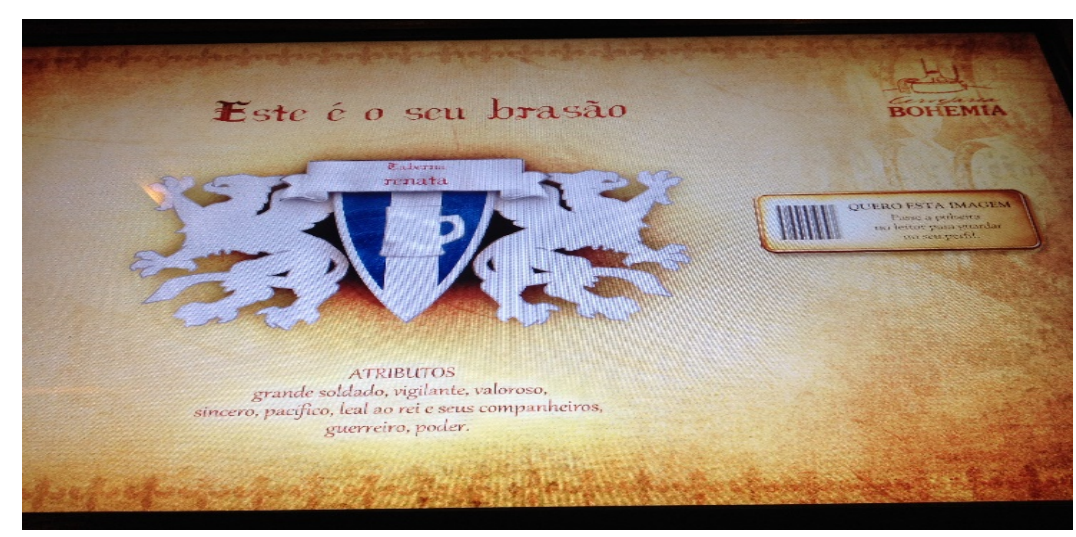

Fonte: Acervo dos Pesquisadores

Figura 4. Trecho das tavernas e dos brasões medievais

Como se pode observar à direita do brasão em "quero essa imagem", o visitante poderia registrar a imagem em sua pulseira a partir do código de barras, de modo que a imagem do brasão formado poderia ser enviada para e-mails e redes sociais. Esse aparato costumava gerar especial interesse dos visitantes, como pais e mães com filhos e filhas que se juntavam para construir o brasão 
da família. A formação de brasões com atributos buscava dar aos visitantes um lugar pretensamente nobre de acordo com a sua personalidade. No caso do brasão medieval formado acima, se apresentavam os seguintes atributos: "grande soldado, vigilante, valoroso, sincero, pacífico, leal ao rei e seus companheiros, guerreiro, poder". Ainda a partir do brasão medieval que se formava, observa-se, no canto superior direito, a identidade visual da marca da cerveja Bohemia inserida no aparato no contexto da diversão (Holbrook, 2000). Esses achados corroboram com o estudo de Fontanelle (2013) sobre como o processo de construção da imagem da marca está em consonância com os valores da época, pois a diversão foi um dos elementos que influenciariam a escolha de Ronald do McDonalds e todo o universo mitológico do circo, buscando reproduzir o espetáculo da hiper-realidade.

A noção de hiper-realidade, tal como apontada nos estudos de Adorno e Horkheimer (1985), Baudrillard (2008) e outros, pode ser tecida por meio de mecanismos de dominação ideológica, a qual busca inconscientemente, a partir de uma estratégia de espetacularização, produzir um "simulacro" desta suposta realidade, gerando o fenômeno da distopia. De acordo com os achados de Fontanelle (2013), as lanchonetes do McDonalds buscariam transmitir uma experiência de diversão em concomitância com os contornos da sociedade que se delineava na década de 1960, quando a sociedade norte-americana já seria entendida como a sociedade do entretenimento, do lazer e do espetáculo. A ênfase na diversão seria um valor central da imagem que o McDonalds buscava transmitir aos seus consumidores, em função da própria formação dos valores e do modo de vida do consumidor alvo: a família de classe média norte-americana. Do pós-guerra em diante, a ações de promoção começariam a construir e a contar narrativas associando seus produtos e serviços a mitos sedimentados no imaginário norte-americano.

Como assinala Fontanelle (2013), o uso intensivo da experiência no setor de serviços de alimentação busca reforçar o lugar da marca com atributos com os quais o consumidor possa se identificar, em um processo no qual a marca aciona sentidos que buscam preencher o vazio existencial deixado pela sociedade de consumo, na qual tudo se torna descartável. Um exemplo é a cafeteria Starbucks, que buscaria se diferenciar como um espaço em que possibilita certa experiência do lugar, o que pode ser notado pela existência de uma mobilha estilizada, iluminação parcial, enfim, um lugar onde é possível tomar café se ouvindo jazz. Nesse contexto, conforme a lógica trazida por Holbrook e Hirschman (1982), o fun ocuparia um espaço central nas relações de experiências advindas das ações de marketing que propõem interação direta com o consumidor.

\section{CONSIDERAÇÕES FINAIS}

0 presente trabalho se baseou na teoria crítica objetivando analisar a visitação promovida aos consumidores no CECB para entender o processo discursivo e, assim, buscar identificar as estratégias de produção de sentido na sala Saga da Cerveja junto aos consumidores. O estudo se dedicou a interpretar a elaboração discursiva de cunho ideológico no processo de significação da cerveja por meio da experiência de visitação ao longo do percurso. Assim, a partir das análises realizadas foi possível problematizar as estratégias do marketing de experiências no contexto da produção de sentidos sobre a marca de cerveja Bohemia. A descrição de elementos do percurso permitiu associar o CECB a um local de diversão e entretenimento.

Ao longo da experiência, o espetáculo da hiper-realidade é acionado por meio da construção de uma narrativa sobre a história da cerveja contada sob a ótica de uma saga, que se expressa na significação de valores como aventura, tradição, nobreza e distinção. Assemelha-se, assim, nas devidas proporções, a outros espaços de entretenimento, como a própria Disney, figurando, quiçá, como um parque de diversão dos adultos, uma vez que se debruça sobre o tema da cerveja, cujo consumo é proibido para menores de 18 anos.

As estratégias utilizadas buscavam proporcionar uma experiência de visitação na qual o consumidor pudesse criar vínculos com a marca a partir de atributos valorativos. Um exemplo, que ilustra essa dinâmica no percurso analisado, se refere ao aparato que propõe ao visitante criar um brasão de sua família com valores que supostamente lhe corresponderia. Esse movimento de aproximação e personalização da marca, relacionada ao acionamento de valores individuais, denota no 
Produção de Sentidos na Indústria Cultural da Cerveja: Aspectos do processo discursivo nas ações de marketing de experiências

contexto da indústria cultural o intuito de preencher o vazio existencial deixado pela sociedade de consumo.

A análise do CECB, vinculada organização produtiva Ambev, que detém a marca Bohemia, revela nuances de como a produção de sentidos se configura como um importante mecanismo de controle e cooptação dos sujeitos no contexto das estratégias de marketing de experiências para o fomento do consumo. Os resultados da análise revelam o uso de um processo de significação empreendido por um discurso que se propõe a contar a "história da cerveja" desde o sentido amplo (produto cerveja) até o sentido estrito (marca Bohemia). Contudo, como observado, o conteúdo retórico do discurso é sistematicamente preparado para construir uma rede de significados mediante um processo de sedução focada no espetáculo da hiper-realidade. Desse modo, as estratégias de marketing analisadas buscavam produzir sentidos que remetem ao imaginário de um lugar distante, tanto geograficamente (Europa), quanto no tempo, acionando a ideia da cerveja enquanto "ouro líquido" que resistiria a passagem do tempo chegando aos dias atuais. Assim, a narrativa busca conferir sentidos de continuidade do produto, e mais especificamente da marca, como algo durável, cuja a tradição remonta a tempos longínquos em uma origem situada historicamente.

Assim, se torna necessário que a experiência possibilite ao consumidor se sentir imerso em uma cenografia diferente da habitual, ao mesmo tempo em que recorre à produção de sentidos com os quais possa se identificar, como é o caso do som produzido pelo murmurinho de uma taverna medieval a semelhança do que pode encontrar na experiência do cotidiano ao entrar em bar nos dias atuais. As estratégias da experiência se apropriam de elementos históricos de forma controversa, como no caso de associar a difusão da cerveja na Europa aos romanos e da contradição de uma taverna nobre, enquanto busca conferir à cerveja um lugar social de destaque.

Dessa forma, foi possível identificar que as estratégias de marketing de experiência se referem à produção de status relacionado à cerveja, a exemplo da construção de discursos em que a cerveja é tida como uma bebida que a produção requer saberes acurados, cuja produção é realizada em mosteiros, locais de guarda e difusão de conhecimento. A relação entre os santos cervejeiros, estilos de cerveja e cidades/regiões reforçam a ideia da cerveja enquanto uma bebida de estudiosos e de origem europeia. Na mesma perspectiva, os efeitos de pátina são acionados e emoldurados por uma cenografia que investe na passagem do tempo. Na taverna medieval, o visitante pode produzir brasões colocando seu nome/sobrenome, reforçando sentidos de tradição, o que confere ao consumidor um lugar distinto relacionado à nobreza. A produção do brasão, ainda que esteja associado à nobreza, contrasta, por sua vez, com o lugar social em que, no período medieval, era conferido às tavernas, incorrendo em outra apropriação histórica inadequada. Dessa forma, as estratégias de marketing atuavam por meio da diversão, fazendo com que a experiência no tour cervejeiro se apresente como uma possibilidade de fuga, de preencher o lugar do vazio deixado pela sociedade do consumo de fala Baudrillard (2008), na qual tudo se torna possível, oferecendo produtos e marcas "capazes" de dizer quem somos e onde estamos (Fontanelle, 2013).

Esse processo está longe de ser um ato ingênuo, pois apesar de ser apresentado em um contexto de exercício de aparente liberdade, o produto da significação está direcionado para um resultado específico da aparelhagem social, econômica e ideológica (Adorno \& Horkheimer, 1985). Como se viu na análise, as estratégias se processam em determinado contexto cultural prevendo e buscando condicionar comportamentos de modo a antecipar desejos, que ao serem propostos e compartilhados na experiência do tour, reforçam valores comuns que dão sentido às práticas e às escolhas que formam o gosto por meio da significação ideológica do consumo. Consideramos que os estudos sobre a sociologia do gosto, como propõe a teoria de Bourdieu (2013), podem contribuir às pesquisas de marketing de experiência no contexto da alimentação. Dessa forma, estudos futuros podem ampliar a compreensão sobre a forma como os condicionamentos e comportamentos de classe influenciam a produção de sentidos na configuração das práticas de consumo. 


\section{Referências}

Aaker, J. L. (1997). Dimension of brand personality. Journal of Marketing Research, 34(1), 347-56.

Adorno, T., \& Horkheimer, M. (1985) A dialética do esclarecimento: fragmentos filosóficos. Rio de Janeiro: Jorge Zahar.

Alcadipani, R., \& Hodgson, D. (2009). By any means necessary? Ethnographic access, ethics and the critical researcher, Tamara: Journal of Critical Postmodern Organization Science, 7(3-4), 127-146.

Almeida, V.C.; \& Rocha, A. (2008). Efeito pátina: a inscrição de signos conotativos da passagem do tempo nos bens de consumo. Comunicação, mídia e consumo. 5(13), 97-120.

Araujo, F.F., Bitar, N.P., Santos, M., Baião, M.R., \& Silva, T. (2019). Experiências de Consumo no Samba. Revista Alceu, 20(38), 142-163.

Araujo, F. F., \& Chauvel, M. A. (2012). Marketing de Cinema Francês no Brasil: Um estudo exploratório sobre as estratégias de promoção para o lançamento de filmes no mercado brasileiro. FACEF Pesquisa: Desenvolvimento e Gestão, vol. 15(3), 298-315.

Araujo, F. F., \& Rocha, A. (2016). Significados Atribuídos ao Lazer na Terceira Idade: Observação Participante em Encontros Musicais. Podium: sport, leisure and tourism review, 5(2), 38-55.

Araujo, F.F., \& Rocha, A. (2019). The redefining of later life through leisure: music and dance groups in Brazil. Leisure Studies, 38(5), 712-727.

Araujo, F. F., Turano, L. M., \& Vieira, F. C. (2019). Subculturas Religiosas de Consumo: Um estudo etnográfico de jovens católicos nas práticas dos Exercícios Espirituais. Consumer Behavior Review, 3(2), 99-119.

Azambuja, C. P., \& Bichueti, R. S. (2016). Marketing de Experiência: Estratégias para Impulsionar o Market Share e Fortalecer a Marca do Energético Energy. Revista de Administração da UFSM, 9(Edição Especial), 88-106.

Bamforth, C. (2008). Vinhos versus Cervejas: uma comparação histórica, tecnológica e social. São Paulo: Senac.

Bardin, L. (2011). Análise de conteúdo. Lisboa: Edições 70.

Baudrillard, J. (2008). A Sociedade de Consumo. Lisboa: Edições 70.

Beltramelli, M. (2012). Cervejas, brejas e birras: um guia complete para desmistificar a bebida mais popular do mundo. São Paulo: Leya.

BJCP. (2015). Diretrizes de Estilo para Cerveja do Beer Judge Certification Program (BJCP). Recuperado em 20 abril, 2000, de https://www.bjcp.org/docs/2015_Guidelines_Beer.pdf.

Bourdieu, P. (2013). O senso prático. Petrópolis: Vozes.

Brakus, J. J., Schmitt, B. H., \& Zarantonello, L. (2009). Brand experience: What is it? How is it measured? Does it affect loyalty? Journal of Marketing, 73, 52-68.

Brito, S.R, Oliveira, A.M., Nobre, L.H.N, \& Macêdo, A.F.P. (2017). Dimensões de Brand Experience no Contexto Brasileiro. RACE, Joaçaba, 16(4), 121-146.

Carneiro, V. C. V. (2011). A análise do discurso como instrumento de pesquisa para os estudos em sustentabilidade. In: III Encontro de Ensino e Pesquisa em Administração e Contabilidade. Anais... João Pessoa: Anpad.

Cervieri Júnior, O., Teixeira Júnior, J. R., Rangel, G., Rawet, E. L. \& Silveira, C. T. J. (2014). 0 setor de bebidas no Brasil. BNDES Setorial. Rio de Janeiro, 40.

Cruz, C.O., Prado, S.D., Freitas, R.F., Ferreira, F., \& Carvalho, M.C.V.S. (2013). Alimentação, publicidade e identidade no universo do consumo. In: Ferreira, F., Prado, S. D., \& Carvalho, M. C. V. S. (Org.). Alimentação, Consumo e Cultura. 1a. Ed. Curitiba: CRV, p. 155-179.

Decreto no 9.902 de 08 de julho de 2019 (2019). Altera o Anexo ao Decreto no 6.871, de 4 de junho de 2009. Diário Oficial da União. Brasília, DF: Secretária-geral da Presidência da República.

Detienne, M. (1988). Dioniso a céu aberto. Rio de Janeiro: Jorge Zahar.

Ding, D. X., Hu, P. J., Verma, R., \& Wardell, D. G. (2010). The impact of service system design and flow experience on customer satisfaction in online financial services. Journal of Service Research, Thousand Oaks, 13 (1), 96-110. 
Produção de Sentidos na Indústria Cultural da Cerveja: Aspectos do processo discursivo nas ações de marketing de experiências

Elliot, R., \& Jankel-Elliot, N. (2003). Using ethnography in strategic consumer research. Qualitative Market Research, 6(4), 215-223.

Fernandes, J. A. (2004). Selvagens bebedeiras: álcool, embriaguez e contatos culturais no Brasil colonial. Tese de Doutorado em História. Niterói: UFF.

Flandrin, Jean-Louis. (2015). Tempero, cozinha e dietética nos séculos XIV, XV e XVI. In: Flandrin \& Montanari. História da Alimentação. São Paulo: Estação Liberdade, 478-495.

Fontenelle, I. A. (2013). O nome da marca: McDonald's, fetichismo e cultura descartável. São Paulo: Boitempo/Fapesp.

Habermas, J. (1989). Theory of communicative action: lifeworldand systems a critique. Boston: Beacon Press, v.2.

Griffith, D.A. (2003). Intimacy, rites of passage and social support: symbolic meaning from lifetime shopping experiences. The International Review of Retail, Distribution and Consumer Research, 13(3), 263-278.

Holbrook, M. B., \& Hirschman, E. C. (1982). The experiential aspects of consumption: consumer fantasies, feelings and fun. Journal of Consumer Research, 9(1), 132-140.

Holbrook, M. B. (2000). The Millennial Consumer in the Texts of Our Times: Experience and Entertainment. Journal of Macromarketing, 20(2), 178-192.

Interbrand. (2020). Ranking das marcas brasileiras mais valiosas do mercado em 2019. Recuperado em 29 de abril, 2020, de https://www.interbrand.com/br/best-brands/best-brazilianbrands/2019/ranking/.

Lei no 8.918, de 14 de julho de 1994 (1994). Dispõe sobre a padronização, a classificação, o registro, a inspeção, a produção e a fiscalização de bebidas. Diário Oficial da União. Brasília, DF: Casa Civil.

Lira, J. S., Silva Junior, O. G., \& Costa, F.Z.N. (2020). Como se dá o Engajamento do Consumidor em um Espaço Colaborativo: Relação de negócios ou devoção? Consumer Behavior Review, 4(1), 53-65.

Marques, T. C. N. (2014). A cerveja e a cidade do Rio de Janeiro: De 1888 ao início dos anos 1930. Brasília: EdUNB/Paco Editora.

Matsunobu, K. (2018). Music for life: A Japanese experience of spirituality, ageing and musical growth. Ageing \& Society, 38(6), 1100-1120.

Mhlanga, 0., \& Tichaawa, T. M. (2017). Influence of social media on customer experiences in restaurants: A South African study. Turizam, 65(1), 45-60.

McCracken, G. (2003). Cultura \& Consumo: Novas Abordagens ao Caráter Simbólico dos Bens e das Atividades de Consumo. Rio de Janeiro: Ed. Mauad.

Meyer, C., \& Schwager, A. (2007). Understanding customer experience. Harvard Business Review, Boston, 85, 117-126.

Moura, L.P.A., \& Araujo, F.F. (2020). Influência dos Pares nas Práticas de Consumo: Análise do grupo de referência no Filme Meninas Malvadas. Consumer Behavior Review, 4(1), 1-18.

Montanari, M. (2015). Plena e baixa Idade Média (séculos XI-XV). In: Flandrin, Jean-Louis \& Montanari, M. História da Alimentação. 8a ed. São Paulo: Estação Liberdade, 381-386.

Monteiro, R., \& Gouvêa, G. (2016). Centro de Experiência Cervejeira da Bohemia: um Museu de Ciência e Tecnologia? ALEXANDRIA. Revista de Educação em Ciência e Tecnologia, 9(2), 303-327.

Pine II, B. J., \& Gilmore, J. H. (1998). Welcome to the experience economy. Harvard Business Review, July-August, 97-105.

Rosa, S. E. S., Cosenza, J. P. \& Leão, L. T. S. (2006). Panorama do setor de bebidas no Brasil. In: BNDES Setorial, Rio de Janeiro, 23, 101-150.

Schivelbusch, W. (1992). Tastes of Paradise: a social history of spices, stimulants, and intoxicants. Tradução: David Jacobson. New York: Vintage Book.

Schmitt, B. H. (2001). Marketing Experimental: das características e benefícios às experiências. São Paulo: Nobel.

Schmitt, B.; Brakus, J. J.; \& Zarantonello, L. (2014). From experiential psychology to consumer experience. Journal of Consumer Psychology, 25(1), 166-171.

Schmitt, B. H., Brakus, J., \& Zarantonello, L. (2015). The current state and future of brand experience. Journal of Brand Management, 21(9), 727-733. 
Scussel, F.B.C. (2019). Is Consumer Experience the Next Best Thing? Reflections from a systematic review and research agenda proposition. Consumer Behavior Review, 3(2), 57-69.

Shamim, A., \& Butt, M. M. (2013). A critical model of brand experience consequences. Asia Pacific Journal of Marketing and Logistics, 25(1), 102-117.

Silva, M.J.B., \& Barbosa, M.L.A. (2018). Compartilhando Bicicletas e Consumindo Experiências: Uma Investigação do consumo Colaborativo Praticado por Usuários do Bike PE. Consumer Behavior Review, 2(Edição Especial), 1-18.

Silva, S. (2012). A persuasão na propaganda de cervejas: sob o enfoque sistêmico-funcional. Dissertação de Mestrado. Programa de Pós-Graduação em Linguística Aplicada e Estudos de Linguagem, Pontifícia Universidade Católica de São Paulo, São Paulo, SP, Brasil.

Strauss, A. \& Corbin, J. (2008). Pesquisa qualitativa: técnicas e procedimentos para o desenvolvimento de teoria fundamentada. (2 $\left.{ }^{\mathrm{a}} \mathrm{Ed}\right)$. Porto Alegre: Artmed.

Vargo, S. L., \& Lusch, R. F. (2004). Evolving to a new dominant logic for marketing. Journal of marketing, 68(1), 1-17.

Tripadvisor. (2020). Avaliações do Centro de Experiência Cervejeira da Bohemia. Recuperado em 5 de maio de 2020, de https://www.tripadvisor.com.br/ShowUserReviews-g303504-d3246285r724225085-Cervejaria_Bohemia-Petropolis_State_of_Rio_de_Janeiro.html\#REVIEWS.

Venturini Filho, W. G. (2010). Bebidas alcoólicas: ciência e tecnologia. São Paulo: Blucher.

Thompson, C.J. (1997). Interpreting Consumers: A Hermeneutical Framework for Deriving Marketing Insights from the Texts of Consumers' Consumption Stories. Journal of Marketing Research, $34(1), 438-455$.

Thompson, J. B. (2000). Ideologia e cultura moderna: teoria social crítica na era das comunicações de massa. Petrópolis: Vozes.Yamamoto, C. H. (2011). A demanda por bebidas alcoólicas no Brasil: 2008-2009. Dissertação de Mestrado. Escola de Economia de São Paulo. São Paulo: FGV. 